\title{
Developing and Validating a Construct of Entrepreneurial Intensity
}

Jianwen Liao

Patrick J. Murphy

Harold Welsch

$I$ $n$ this article we define, validate, and propose a construct of entrepreneurial intensity, or the degree of entrepreneurship in firms. First, in defining the construct, we explore theoretical differences between entrepreneurial intensity and orientation in order to distinguish it. Second, we empirically validate a measure of entrepreneurial intensity using data based on a sample of 563 entrepreneurs. Third, we propose avenues for research on how entrepreneurial intensity distinguishes entrepreneurs and entrepreneurial action. Finally, we detail theoretical implications of using entrepreneurial intensity as an antecedent and outcome

The entrepreneurship field has been concerned traditionally with questions such as "Who are entrepreneurs?" or "What distinguishes them from other types of people?" Significant attention has been devoted to identifying entrepreneurial characteristics and personal attributes to differentiate them from general public and small businessowners (Shaver and Scott 1991). There has also been considerable interest in the ability to identify the psychological characteristics of these individuals so as to describe how entrepreneurs differ from other individuals (Low and MacMillan 1988). For example, many personality traits have been used to typify entrepreneurs, including ambition, need for achievement, risk taking, and locus of control (Brockhaus 1982; Casson 1982; McClelland 1961). However, this body of research is fragmented and inconclusive. It has produced no clear evidence that psychological attributes differentiate entrepreneurs from other individuals. Some research goes even further, saying it is the wrong research question (Gartner 1985), not a viable research approach (Bull and Willard 1993), or simply futile (Low and Macmillan 1988).

In a study involving members of the National Federation of Independent Business (NFIB), Cooper and Dunkelberg (1986) indicate several paths by which one might become a small businessowner, including founding the business, purchasing business, inheriting the business, and being promoted or brought in by other owners. Using NFIB data, they tested hypotheses delineating significant individual-level differences in entrepreneurship intensity (EI), or "degree of entrepreneurship." Although Cooper and Dunkelberg suggest the construct may not be directly measurable or observable, they do imply that it may be inferred through reflection in a set of characteristics identified in previous research (Keats and Bracker 1988: 62). These characteristics include background, attitudes, and a complex set of factors associated with previous careers, incubator organizations, and the processes of starting. These characteristics collectively reflect EI. To date, despite this attention, no widely accepted empirical or operational measure of "entrepreneurial intensity" exists.

Entrepreneurial intensity has foundations in the notion of a "Protestant work ethic" (Weber 1905) and the need for achievement (McClelland 1961).Additionally, it has a secondary basis in commitment, internal locus of control, diligence, and determination. Despite religious pluralism in U.S. society, the cultural effects of Protestantism have exerted a powerful influence on thoughts and action since the early history of the country, with the main thrust asserting that spiritual salvation is attainable through hard work. More recently, the concept has evolved outside of a religious context. In this role, it assumes hard work is for material benefit and personal recognition only. Thus, it has evolved into a version of a Type-A behavior.

In early characterizations, Type-A behavior was identified by an excessive competitive drive with enhanced sense of time urgency. Later, additional aspects were defined, including (1) an intense sustained desire to achieve, (2) eagerness to compete, (3) persistent drive for recognition, (4) continuous involvement in deadline activities, (5) habitual propensity to accelerate mental and physical functions, and (5) consistent alertness. Price (1982) suggested these behavioral patterns are learned in open, competitive economies where high upward mobility is possible. The overall notion assumes success is a function of individual effort and progress is definable in terms of material or tangible achievements. The visualization of a successful entrepreneurial venture, combined with sources of parental and spousal support, the "right" circumstances (e.g., life stage, education, rich environments), can cause an individual to generate a "fire in the belly" or high "environmental intensity." This level of commitment, when channeled into an entrepreneurial endeavor, characterizes the passion required for entrepreneurial success (Selz 1992). The same passion is contextualized by a single-minded focus to start a business and work toward its survival and growth, often at the expense of other important goals. 


\section{Defining Entrepreneurial Intensity}

Much of the theoretical rationale for EI was developed and refined through issues generated from empirical research attempts in Europe regarding the specific nature (e.g., regarding culture) of intentions and behaviors heralded by the construct. The first issue posits that central and eastern Europeans unlearned certain aspects of the work ethic by being provided with secure jobs and social benefits from socialist governments. As a result, entrepreneurial intensity is misapplied or nonexistent. The counterargument to this position points out that Weber's (1905) Protestant work ethic originated in Europe and is inherent to all European culture. Thus, individuals are indeed hard workers who exhibit sacrifice, determination, diligence, and a focused commitment to entrepreneurship suppressed temporarily by the socialist governments. From this, the counterargument holds, entrepreneurial intensity is relevant and exists in those environments, too. As a result, this issue begs the question, "What causes entrepreneurial intensity-nature or nurture?" Whereas comparative research across countries focusing on this question does not yet exist, our preliminary results show EI to be more related to entrepreneurial motivations, willingness to make sacrifice and incur opportunity costs, intentions to grow the business, and various demographic variables. Thus, EI reflects aspects of nature and nurture, promising to throw light on how culture and history impact EI from an anthropological perspective as well as an individual one.

EI measures the focus and commitment of entrepreneurs regarding their entrepreneurial ventures. Focus refers to the extent to which an entrepreneur gives up other pursuits to create and own a business and work for the health of the venture. Commitment refers to the extent to which an entrepreneur spends time and resources on venture creation with a passion for development and growth. To illustrate, individuals have multiple potential commitments, both professional and organizational.There are many potential commitments at different levels for entrepreneurs, across short or long stretches of time, such as unions, professional associations, work groups, jobs, or tasks. Entrepreneurs may also be committed to themselves or elements outside of the workplace, such as recreational groups or family. Entrepreneurs may be committed to other people as well as the values and goals of those people. However, the EI construct assumes that entrepreneurs channel the highest effort toward and place the highest value on the success of their enterprise instead of focusing on any of these other possible commitments. We propose that dimensions of focus and commitment are the primary dimensions of entrepreneurial intensity.

\section{Entrepreneurial Intensity versus Entrepreneurial Orientation}

Entrepreneurship orientation (EO) is defined as processes, practices, and decision-making activities leading to the creation of a new venture (Lumpkin and Dess 1996). Its key dimensions are autonomy, innovativeness, risk taking, proactiveness, and competitive aggressiveness. Each dimension is useful in predicting the creation, survival, and performance of a venture (Wiklund 1999).

$\mathrm{EO}$, when measured at the individual level, is related to categorical directionality and describes the propensity for someone to lead a new venture. By contrast, EI captures the degree of entrepreneurship, the level of commitment and focus in leading a new entry.Thus, EO and EI are complementary ${ }^{1}$ and distinct from each other. Research has placed great attention on EO and its relationship to venture creation and performance. However, questions remain regarding how EI further affects venture creation and performance, and how it interplays with contextual and other individual-level factors (Morris and Kuratko 2002). By clarifying and validating EI, studies will shed much needed new light on many contentious and inconclusive findings in entrepreneurship research.

\section{Development of the Entrepreneurial Intensity Scale}

The EI scale described in this article has been administered successfully in the United States, Mexico, Russia, Poland, Romania, Hungary, and several Baltic countries. Entrepreneurs in various stages of development and various industries in these countries have responded to the items on a five-point scale. Preliminary alpha coefficients indicate scale reliability ranges in the low seventies to low eighties (Pistrui et al. 1997; 2000).

Based on the assumption that EI is not directly observable but inferable through reflection in a complex set of factors (Cooper and Dunkelberg 1996), we developed a scale of 12 EI items pretested successfully in 10 different countries (Welsch 1998; Gundry and Welsch 2001).

Table 1 shows that the initial pilot study data using the Entrepreneurial Profile Questionnaire (EPQ) suggests 4 of the 10 items capture entrepreneurial intensity and achieve acceptable scale reliability (Welsch 1998). These items are:

1. Owning my own business is more important than spending time with my family.

2. There is no limit as to how long I would give a maximum effort to establish my business.

3. I would rather own my own business than pursue another promising career.

4. My personal philosophy is to do "whatever it takes" to establish my own business. 
Table 1.

Entrepreneurial Intensity Items

EI Item

PSED Item Number

My personal philosophy is to do "whatever it takes" to establish

QL1F

my own business.

I plan to eventually sell my business.

QL1D

I would rather own my own business than earn a higher salary

QL1G

employed by someone else.

Owning my own business is more important than spending more

time with my family.

I would rather own a business than pursue another promising career.

QL1E

My business is the most important activity in my life.

I will do whatever it takes to make my business a success.

There is no limit as to how long I would give a maximum effort to establish my business.

I would be willing to make significant personal sacrifices in order to stay in business.

I would go to work somewhere else only long enough to make another attempt to establish my own firm.

We included the EI scale items in a survey containing other items related to locus of control, self-efficacy, and sociability. The survey was administered to entrepreneurs and a neutral comparison group. For both groups, the items were preceded by the statement, "The following statement can be used to describe most people. How accurately would they describe you?" Respondents indicated accuracy via a Likerttype scale ranging from 1 (completely untrue) to 5 (completely true).

\section{Method}

\section{Sample and Procedure}

The data for this study were obtained from the Panel Study of
Entrepreneurial Dynamics (PSED). The PSED is a longitudinal data set of individuals in the process of starting businesses who were identified from a random-digit dialing telephone survey of 31,261 adults in the United States who are 18 years of age or older.A nascent entrepreneur is identified if he or she answered yes to the following two questions:(1) Are you, alone or with others, now trying to start a new business? (2) Are you, alone or with others, now starting a new business or new venture for your employer? Is the effort a part of your job assignment? All of these individuals were considered candidates for the nascent entrepreneur interview if they met three additional criteria. First, they expected to be owners or part owners of the new firm. Second, they had been active in trying to start 
the new firm in the last 12 months. Third, the effort was still in the start-up or gestation phase and was not an infant firm. Follow-up surveys were conducted at 12-month intervals to evaluate the status of the start-up effort. Data related to nascent entrepreneurs were collected using a combination of survey and telephone interviews. Survey questionnaires included items related to opportunity recognition, entrepreneurial climate, start-up problems, start-up context, and reasons for starting a new venture as well as nascent entrepreneurs' demographics, background, and personal dispositions. Telephone interview questions were concerned with the nature of the start-up, start-up activities, start-up team, and the start-up funding requirements, future expectations for the new business, personal decision-making style, and market and competition assessments as well as nascent entrepreneurs' social networks. The data set consists of 830 nascent entrepreneurs and 431 general public.A more detailed description of the background and methodology of the PESD data set can be found in Gartner, Shaver, Carter, and Reynolds (2004).

\section{Preliminary Screening and Analyses}

For all parametric analyses that assume certain population characteristics (e.g., normal distribution, homogeneity of variance), post-stratification weights accompany the PSED data set based on estimates from the U.S. Census Bureau's most recent population survey. The weights adjust sample findings based on gender, age, household income, and geographic region. This produces 144 cells for weighting adjustment (Reynolds 2000: 177). These weights promote wide generalizability of study findings using PSED data (Reynolds 2000:181). Further details regarding the creation and application of weights are described in Reynolds (2000). The primary data consisted of 751 combined observations, and listwise deletion (SPSS 12.0), based on missing data, yielded a usable sample of 563 cases representing entrepreneurs and a nonentrepreneur control group.

Multivariate Normality. Structural Equation Modeling (SEM) assumes multivariate normality of study variables and all linear combinations of variables. Using PRELIS, we screened scale items for univariate and multivariate normality. In all cases, items were skewed and kurtotic. However, by virtue of sample size and inspection of relevant indices (e.g., the variance inflation factor), skewness and kurtosis did not indicate extreme departures from normality of the sort to threaten the reliability or validity of study results (Tabachnik and Fidell 1996).

Confirmatory Factor Analysis. Using LISREL 8 (Joreskog and Sorbom 1993), we estimated reliability and validity of our measurements based on SEM results. We examined all relevant indices and coefficients for unsuitable estimates or values outside acceptable limits. This examination included negative error variance of observed variables, extreme standardized coefficients, and unduly large standard errors for estimated coefficients. All values were satisfactory, and we detected no violations of analysis criteria.

\section{Results \\ Main Analyses}

Multiple measures assessed overall model fit to the observed pattern of correlation in the data (Hair,Anderson, Tatham, and Black 1995). Our $\chi^{2}$ statistic was 3.08 ( $\left.\mathrm{df}=2 ; p=.214\right)$, demonstrating the model did not differ significantly from the data. The goodness-of-fit index (GFI) assesses fit between the observed covariance matrix and the one forecasted by the model. Our GFI statistic was .99, exceeding the generally acceptable value of 90 , giving evidence of good fit between model and data. The adjusted goodness-of-fit index (AGFI), which assesses model parsimony by evaluating model fit in terms of the number of estimated parameters required to achieve the level of fit, was .98, greater than the recommend-

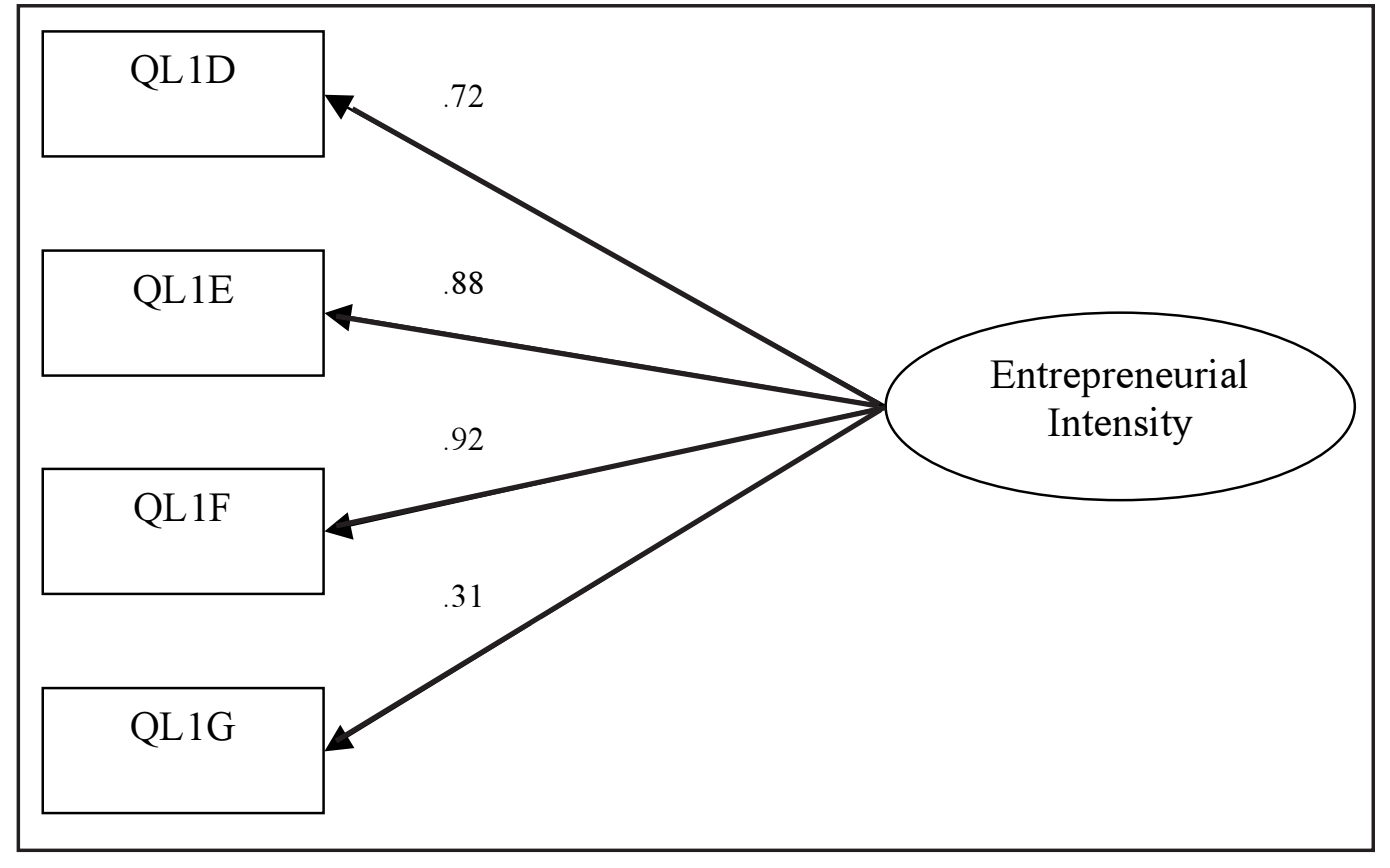

Figure 1. Confirmatory Factor Analysis: Entrepreneurial Intensity 
ed level of .90. The root mean square residual (RMSR) is the average of the residuals between observed and estimated input covariance matrices. Our RMSR statistic was .031, superior to the recommended value of .06 . Overall, these fit indices show strong evidence that our model is representative of the observed data.

We evaluated our measurement model by construct convergent validity. Convergent validity can be tested by examining the significance of the path coefficient on its posited latent variables. As indicated in Figure 1, all the path coefficients included in the measurement models are statistically significant $(\mathrm{p}<.05)$, providing evidence of convergent validity.

Following Hair et al. (1995), we used the following formula to calculate the composite reliability of entrepreneurial intensity:

$$
\text { Construct reliability }=\frac{\left(\sum \mathrm{sd}, \text { loading }\right) 2}{(\Sigma \mathrm{sd}, \text { loading }) 2+\left(\Sigma \varepsilon_{\mathrm{j}}\right)}
$$

where standardized loadings are obtained directly from the program output and $\varepsilon_{j}$ is the measurement error for each indicator. Construct reliability for our model was .769, exceeding the recommended value of .50 for this statistic.

\section{External Validity: Entrepreneurial Intensity as a Differentiator}

As described above, prior research on traits and person-centric attributes has failed to yield factors differentiating entre- preneurs and nonentrepreneurs. For example, high degrees of risk-taking characteristics do not describe entrepreneurs because nonentrepreneurs frequently exhibit high risk-taking characteristics. Using a construct of EI, which derives from personal and contextual foundations, we tested whether EI differentiates entrepreneurs from nonentrepreneurs. We did this by creating two groups (392 entrepreneurs and 175 non entrepreneurs) and examining the differences between groups across the four EI items. Table 2 presents results. The two groups differed significantly across the entrepreneurial intensity items, providing evidence that entrepreneurial intensity is an important factor in differentiating nascent entrepreneurs.

\section{Discussion and Conclusions}

A construct of EI is central and pivotal to the entrepreneurial process. When operationalized as a study variable, it promises to contribute substantially to the development of future entrepreneurship theory. As such, future entrepreneurship research should build on this foundation and explore EI further in different contexts, in terms of antecedents and outcomes, as illustrated in Figure 2.

\section{Contributions to Future Research}

Entrepreneurial Intensity Antecedents. EI is related to environmental as well as individual-level antecedents. Future research on EI should investigate and delineate the degree to which entrepreneurs reporting high EI engage in behaviors

\begin{tabular}{|c|c|c|c|}
\hline & MEANS & & \multirow{2}{*}{$\begin{array}{c}A N O V A \\
F \text {-test }\end{array}$} \\
\hline & $\begin{array}{c}\text { Nascent } \\
\text { Entrepreneurs }\end{array}$ & $\begin{array}{c}\text { Comparison } \\
\text { Group }\end{array}$ & \\
\hline $\begin{array}{l}\text { QL1D: I would rather own my own business } \\
\text { than earn a higher salary employed by } \\
\text { someone else. }\end{array}$ & 4.05 & 3.27 & $69.712^{*}$ \\
\hline $\begin{array}{l}\text { QL1E: There is no limit as to how long I } \\
\text { would give a maximum effort to establish } \\
\text { my business. }\end{array}$ & 3.90 & 3.36 & $30.219^{*}$ \\
\hline $\begin{array}{l}\text { QL1F: My personal philosophy is to do } \\
\text { "whatever it takes" to establish my own } \\
\text { business. }\end{array}$ & 3.77 & 2.91 & $77.662 *$ \\
\hline $\begin{array}{l}\text { QL1G: Owning my own business is more } \\
\text { important than spending more time with my } \\
\text { family. }\end{array}$ & 1.77 & 1.65 & $6.068^{*}$ \\
\hline$* p<.01$ & & & \\
\hline
\end{tabular}
leading to entrepreneurial successes in the start-up phase

Table 2. Analysis of Variance: Nascent Entrepreneurs and Comparison Group 


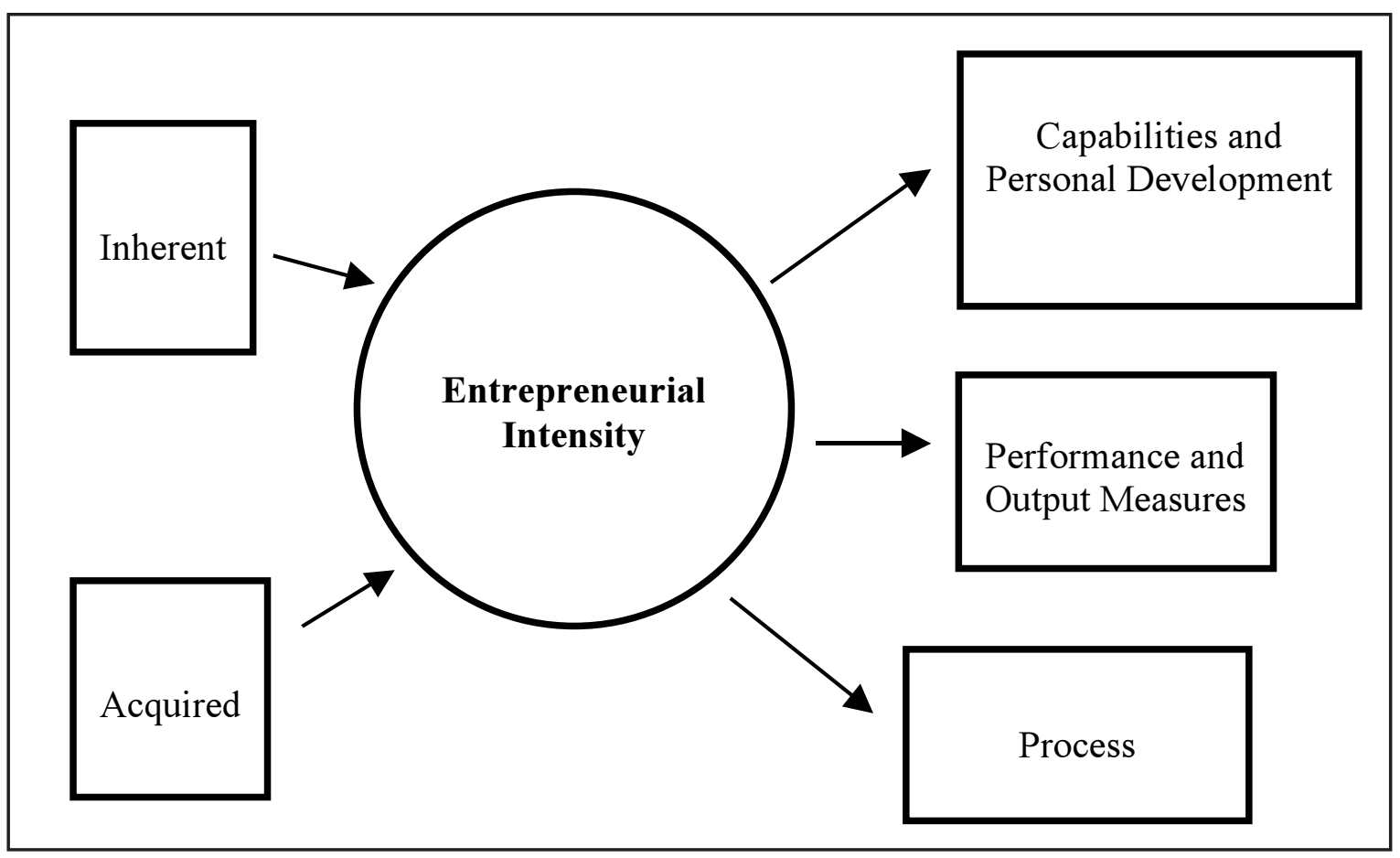

Figure 2. Entrepreneurial Intensity: Antecedents and Outcomes

such as receiving funding, generating sales, profitability, and achieving survivability and growth. The theoretical framework suggests that EI impacts task motivation along with the degree to which an individual perceives he or she has the ability for high achievement and success. Thus, EI should be researched in concert with other constructs, such as locus of control or entrepreneurial orientation. A second research issue is whether EI is a stable variable over time, throughout the entrepreneurial process, or a transient variable with different impacts in different contexts. In addition, there may be substantial differences in the degree of entrepreneurial intensity between types of entrepreneurs, for example, those in high-technology industries versus those running family firms.

Issues of whether EI is intrinsic versus learned remain open; similar to issues of whether entrepreneurs are born versus made. Both explanations, to be sure, are likely correct: certain dispositions such as aggressiveness, impulsiveness, tendency for action, or extroversion vary across people, and these seem to be related to EI. However, learned or acquired behaviors stemming from experiences of observing family members or role models perform successful entrepreneurial behaviors may also impact EI. Future research must consider both kinds of antecedents as research clarifies the EI construct and relates it to outcomes.

Individuals were chosen as the unit of analysis in this research. The primacy of the individual in entrepreneurial research is described by Shaver and Scott (1991). Man, Lau, and Chan (2002) contend the role of the individual entrepre- neur is a major factor of venture competitiveness because of the concentration of decision-making power, which affects firm strategy directly. In addition, Slevin and Covin (1995) suggest the influential role of the entrepreneur is a critical factor in determining the performance of the firm, especially when it remains small. However, future research may investigate average levels of EI in firms, for example, in order to contextualize the construct further.

Entrepreneurial Intensity Outcomes. As shown in Figure 2, EI relates to a series of outcomes that can be categorized into three major groupings of capability, performance, and process. Possessing high EI, as defined, is quite different than the low degree of focus demonstrated by individuals who dabble in multiple projects for only periods of time. Rather, EI individuals have long-term orientations, long attention spans in the context of their ventures, and are not distracted by immediate gratification because they possess entrepreneurial vision.

Other possible outcomes that may result from EI are the ability to start a business, engage in extensive learning behavior, incur broad experiences, acquire high skill, engage in variable activity, develop entrepreneurial competency, engage in personal growth and development, and possess a high EO.This characterization would include having strategic vision with clarity and a greater probability of implementing the vision. Accompanying attitudes include maturity, seriousness, environmental attunement, liability to act, proactivity, and financial success. Performance out- 
comes may include external financing, market share, shortterm success factors such as incorporation and growth, as well as long-term factors such as acquiring companies, longevity, and mergers. Process outcomes to be investigated by future research may include engaging in information absorption, adaptability, developing a wide network with significant relationships, being competitive, enhancing the innovative capability, engaging in and adopting innovations, setting goals and plans, goal accomplishment, and having a greater ability to acquire capital (e.g., financial, human, or informational).

\section{Conclusions}

We have introduced EI as a theoretically distinctive and empirically defensible construct. Using data from real-world entrepreneurs, we have also provided evidence useful for examining its validity and reliability.This contribution to the literature adds a new dimension to explain entrepreneurial phenomena, cutting across traditional theoretical dichotomies (intrinsic versus learned). In concert with other perspectives on entrepreneurship and relevant entrepreneurship-related constructs, this contribution enriches the field with a new construct to help drive future theory building.

\section{Endnotes}

1. This definition of "complementary" is precisely the same as Bohr's (1949: 224; Popper, 1957: 90), which describes complementary approaches or factors as (a) complementary in the usual sense but also (b) mutually exclusive such that to the degree the first is adopted it precludes the adoption of the second.

\section{References}

Bohr, N. 1949. Discussion with Einstein on epistemological problems in atomic physics. In P.A. Schilpp, ed., Albert Einstein: Pbilosopher-scientist. The library of living philosophers 7. La Salle, IL: Open Court Press, 201-241.

Brockhaus, A. L. 1982. The psychology of the entrepreneur. In Eaglewood, C., Encyclopedia of Entrepreneurship. New Jersey: Prentice-Hall, 39-56.

Bull, I., and Willard, G. E. 1993. Towards a theory of entrepreneurship.Journal of Business Venturing 8: $183-195$.

Casson, M. 1982. The entrepreneur: An economic theory. Tatowa, NJ: Barnes \& Noble.

Covin, J. K., and Slevin, D. P. 1995. The influence of the organizational structure on the utility on an entrepreneurial top management style. Journal of Management Studies 25, 3: 217-234.

Cooper,A., and Dunkelberg, W. 1986. Ownership structure and entrepreneurship. Strategic Management Journal 7: $503-522$.

Gartner,W. B. 1985.A conceptual framework for describing the phenomenon of new venture capital. Academy of Management Review 10, 4 (October): 696-706

Gartner, William B., Shaver, Kelly G., Carter, Nancy M., Reynolds, Paul D. 2004. Handbook of entrepreneurial dynamics: The process of business creation. Thousand Oaks, CA: Sage Publications.

Gundry, L., and Welsch, H. 2001. The ambitious entrepreneur: High growth strategies of women based enterprises. Journal of Business Venturing 16, 5 (September): 453-470.

Hair, J., Anderson, R., Tatham, R., and Black, W. 1995. Multivariate data analysis, 5th ed. Englewood Cliffs, NJ: Prentice-Hall. Joreskog, K., and Sorbom, D. 1993. LISREL user's guide. Uppsala, Sweden: University of Uppsala.

Keats, B., and Bracker, J. 1988. Toward a theory of small firm performance:A conceptual model. American Journal of Small Business (Spring): 41-58.

Low, M., and MacMillan, I. 1988. Entrepreneurship: Past research and future challenges.Journal of Management 14: $139-161$.

Lumpkin, G.T., and Dess, G.G. 1996. Clarifying the entrepreneurial orientation construct and linking it to performance. Academy of Management Review 21, 1 (January): 135-172.

Man, T.W.Y., Lau,T., and Chan, K. F. 2002. The competitiveness of small and medium enterprises; A conceptualization with focus on entrepreneurial competencies. Journal of Business Venturing 17: 123-143.

McClelland, D. 1961. The achieving society. New York: Free Press.

Morris, M.H., and Kuratko, D.F. 2002. Corporate entrepreneurship. Mason, OH: South-Western College Publishers.

Pistrui, D., Welsch, H., and Roberts, J. 1997. The [re]-emergence of family business in the transforming Soviet bloc. Family Business Review X, 3 (Fall): 221-237. 
Pistrui, D., Welsch, H., Wintermantel, O., Liao, J., and Pohl, H. 2000. Entrepreneurial orientation and family forces in the new Germany: Similarities and differences between East and West German entrepreneurs. Family Business Review XIII, 3 (September): 251-263.

Popper, K. R. 1957. The poverty of historicism. London: Routledge.

Price, V. 1982. Type A behavior pattern: A model for research and practice. London:Academic Press.

Reynolds, P. 2000. National panel study of U.S. business startups: Background and methodology. In J.A. Katz, ed., Advances in Entrepreneurship, Firm Emergence, and Growth. Stamford, CT: JAI Press, 153-227.

Selz, M. 1992. Young America still fosters entrepreneurial ambitions." Wall Street Journal (April 6), B2.

Shaver, K. G., and Scott, L.R. 1991. Person, process, choice:The psychology of new venture creation. Entrepreneurship: Theory E Practice 16, 2 (Winter): 23-45.

Tabachnik, B., and Fidell, L. 1996. Using multivariate statistics. 3rd ed. New York, NY: HarperCollins Publishing.

Weber, M. 1995. The Protestant ethic and the spirit of capitalism. New York: Knopf.

Welsch, H. 1998. North American entrepreneurs. In Morrison,A., Entrepreneurship:An International Perspective. Oxford: Butterworth Heinemann.

Wiklund, J. 1999. The sustainability of the entrepreneurial orientation-performance relationship. Entrepreneurship:Theory $\varepsilon$ Practice 24, 1 (Fall): 37-48.

\section{About the Authors}

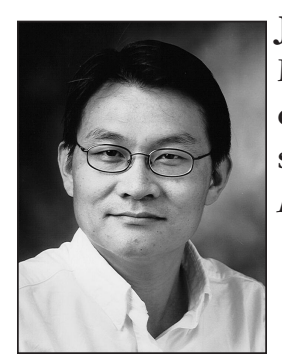

\section{MEjE}

JIANWEN LIAO (j-liao@neiu.edu) is associate professor of management at the College of Business and Management, Northeastern Illinois University. His research expertise and interests are in the areas of venture creation process and entrepreneurial growth strategies. His research has been published in academic journals such as Family Business Review, Entrepreneurship Theory and Practice, Journal of High Tech Management Research, Frontier of Entrepreneurship Research, Journal of Small Business Management, among others.

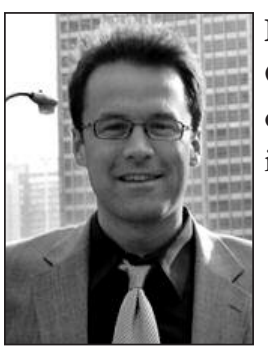

PATRICK J. MURPHY (pmurph12@depaul.edu) is assistant professor of management at the Kellstadt Graduate School of Business, DePaul University. His research emphasizes the conceptual and empirical aspects of entrepreneurial discovery phenomena. He teaches courses and undertakes consulting and outreach activities in the areas of entrepreneurship and management.

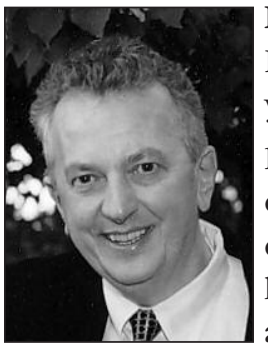

HAROLD WELSCH (hwelsch@depaul.edu) who holds the Coleman Foundation Endowed Chair in Entrepreneurship at DePaul University, has been active in entrepreneurship development for more than 20 years in his role as educator, consultant, researcher, entrepreneur, author, and editor.

Dr. Welsch is well known for his expertise in technology commercialization, privatization of centrally planned economies, entrepreneurship career paths, formal and informal strategic planning, information seeking and decision behavior, ethnic entrepreneurship, economic development, and small business problems. His work has appeared in many journals. He was coeditor of Research at the Marketing/Entrepreneurship Interface and recently published a book, Strategic Entrepreneurial Growth, with Thompson-Southwestern. 